\title{
BACTERIOLOGICAL CONTAMINATION OF EGG PRODUCTS AFTER THERMAL PRESERVATION PROCESSES
}

\author{
K. BOtKa-PETRAK, ${ }^{a}$ T. PETRAK, ${ }^{b}$ H. MEDIĆ,,${ }^{b}$ and P. NOVAKOVIĆc \\ ${ }^{a}$ Department of Anatomy, Histology and Embryology, Faculty of Veterinary Medicine, \\ University of Zagreb, 55 Heinzelova Street, 10000 Zagreb. Croatia \\ ${ }^{b}$ Faculty of Food Technology and Biotechnology, \\ University of Zagreb, 6 Pierottijeva Street, 10000 Zagreb. Croatia \\ ${ }^{\mathrm{c}}$ Faculty of Food Technology, J. J. Strossmayer University, 18 F. Kuhača Street, 31000 Osijek. Croatia
}

(Received: 28 June 1999; revision received: 5 April 2000; accepted: 22 May 2000)

Research was carried out to define the hygienic propriety of thermally treated eggs, i.e. eggs treated at pasteurization temperatures and those stored frozen. The average values of the number of the bacteria in the pasteurized yolk and egg white were $\log 4.9$ and 5.1, respectively, those in the frozen-pasteurized yolk and egg white were $\log 5.5$ and 4.8 and in the frozen yolk and white were $\log 7.0$ and 5.9. The contaminants Salmonella spp., Proteus spp., Staphylococcus aureus, Escherichia coli, Clostridium spp., Clostridium perfringens, Pseudomonas spp., Campylobacter jejuni and Yersinia enterocolitica were tested for 306 samples of pasteurized, frozen and pasteurized and frozen products of eggs, egg-yolks and egg-whites. Presence of Salmonella spp. in the pasteurized yolk was $12 \%$, Clostridium spp. $16 \%$, E. coli $16 \%$ and Proteus spp. $14 \%$, but in the pasteurized egg white those bacteria were present in $10.8 \%, 15.3 \%, 13.8 \%$ and $10.0 \%$. Staphylococcus aureus was isolated in yolk at 4.6 and in white $4.0 \%$ and Clostridium perfringens 4.0 and $1.5 \%$, respectively. The bacteriological flora indicated that the degree of contamination of egg-products depends directly on the degree of initial contamination and correlates with the technological egg-treatment processes applied.

Keywords: egg, yolk, white, bacterial contamination, processing

The quality and hygienic propriety of egg products depend primarily on the quality of the raw material. Although eggs, when compared to other animal foodstuffs, are better protected because of the role of their shells, especially of the cuticule and because of the well-known bactericidal properties of egg-white, however, they are susceptible to undesirable changes under the influence of various factors under unfavorable conditions. The index of the biological value of egg proteins secures for eggs one of the most important places in the process of nourishment, at least from the nutritive point of view. However, like all other foodstuffs, eggs are also potential causes of foodborne diseases. Because of the possibility of infection with the Salmonella group of bacteria, non-specific food contaminants and breakdown products, it is imperative to 
evaluate the hygienic property of eggs. Immediately after laying, the egg is sterile in $95 \%$ of the cases, and the contamination process starts a few hours later, i. e. after the egg has been laid in the external environment. In most cases, egg-infection takes place through the pores of the shell. The degree of the initial contamination within the egg's interior depends on the quality of its shell, the place of infection and on the mechanical and chemical obstacles that are integral parts of the egg. Initially the adherence of bacteria to the surface is not firm; but when a glycocalix is formed through secretion of fibrils, they cling firmly to the surface and the phase of irreversibility begins. This process is a complex one and the nature of fibrils depends on the type of bacteria (HOOD \& ZOTTOLA, 1987; NASCIMENTO, 1992).

Research has shown that the membranes on the surface and beneath the eggshell act as bacteriological filters. The external membrane prevents most, and the internal one all bacteria from entering; so these two membranes together prevent egg-infection for a period of 24 to $96 \mathrm{~h}$.

Furthermore, it has been confirmed that the antimicrobial proprieties of egg white influence the hygienic proprieties of the whole egg. Selectivity toward bacteria derives from high $\mathrm{pH}$ and antibacterial substances including avidin combined with biotin, ovomucoids, inhibitors, flavoprotein in combination with riboflavin, transferrin and particularly lysozyme (REDFIELD \& DOBSON, 1988; VAN DE GUCHTE et al., 1988).

This bacterial propriety of the egg-white acts differently in contacts with different types of bacteria. Nevertheless, lysozyme, a basic bactericidal protein that lyses the cell wall of Gram-positive and Gram-negative bacteria, remains the main protector of the eggs. However, it is also known that lysozyme gradually loses its bactericidal properties, i.e. as the egg grows older. This loss also occurs during the technological process of manufacture when the yolk and the egg white are mixed, and especially at temperatures over $70{ }^{\circ} \mathrm{C}$

The aim of this research was to define the bacteriological microflora, i.e. how much the inherence of bacterial contaminants depends on the thermal conditions of the technological procedures of pasteurization and freezing of the egg-products. Due to the fact that the aim of the already mentioned thermodynamic procedures is the reduction of typical egg bacteria contaminants, they are unavoidable technological factors in an evaluation of egg quality, i.e. their hygienic propriety.

\section{Materials and methods}

Fifty samples of egg white and 50 samples of yolk were chosen at random in eggproduction and manufacture plants, after the eggs were accepted, washed, dried, flash candled and broken. 
Three hundred and six samples of the egg-products were chosen at random after the technological treatment; pasteurized egg white and yolk, pasteurized and frozen egg white and yolk, and also frozen egg white and yolk.

Continuous one-minute-long plate pasteurization was applied at $60{ }^{\circ} \mathrm{C}$ for eggwhite; also continuous two-minutes-long plate pasteurization was applied at $63^{\circ} \mathrm{C}$ for the yolk; and continuous $150 \mathrm{~s}$ slong plate pasteurization was applied at $62{ }^{\circ} \mathrm{C}$ for the whole liquid egg (Pasteurizer, Pasilac, Denmark). Freezing was carried out at a temperature of $-12{ }^{\circ} \mathrm{C}, 48 \mathrm{~h}$.

Since the microbiological picture is the basic indicator of the eggs hygienic quality, the parameters of bacteriological contamination were tested on a group of products (FRONING et al., 1992). Sizes of samples were $200 \mathrm{ml}$ and they were homogenized on a magnetic mixer "Variomag" for five minutes.

The total count of bacteria was determined using the pour plate technique. One $\mathrm{ml}$ physiological saline dilutions of samples were inoculated in PCA (Plate Count Agar, Merck). The plates were aerobically incubated for $72 \mathrm{~h}$ at $30{ }^{\circ} \mathrm{C}$.

Salmonella spp. Homogenized samples $(25 \mathrm{ml})$ were tested for salmonellas by TSB, Rappaport Vassiliadis Broth, XLD-agar (Merck).

Proteus spp. Egg samples $(20 \mathrm{ml})$ were tested for Proteus spp. by EE-enrichment broth (AES laboratorie). After $24 \mathrm{~h}$ at $37^{\circ} \mathrm{C}$, enrichment broth was plated on VRBDagar (Merck) and incubated at $37{ }^{\circ} \mathrm{C}$ for $24 \mathrm{~h}$. Suspected colonies were plated on TSA (AES laboratorie) and incubated for $24 \mathrm{~h}$ at $30^{\circ} \mathrm{C}$. Biochemical identification was carried out. Colonies, which were lysindecarboxilase negative, arginindihydrolase negative and urease positive were considered as Proteus spp.

Staphylococcus aureus. Undiluted samples $(0.1 \mathrm{ml})$ and $0.1 \mathrm{ml}$ of $1: 10$ and 1:100 dilutions were plated on ETGP-Baird-Parker-agar (Merck). Suspicious colonies were tested for coagulase activity as specified in the international standard (ANON, 1983).

Escherichia coli. Samples of eggs $(1 \mathrm{ml})$ were tested for E. coli by pepton water enrichment. After $20 \mathrm{~h}$ at $37^{\circ} \mathrm{C}, 1 \mathrm{ml}$ of the enrichment broth was transferred into $10 \mathrm{ml}$ of EE broth (AES laboratorie) and incubated for $24 \mathrm{~h}$ at $37^{\circ} \mathrm{C}$. Enrichment broths were plated on VRBD-agar (Merck) and after $24 \mathrm{~h}$ suspected colonies were plated on CASOagar (Merck). After incubation at $30^{\circ} \mathrm{C}$ for $24 \mathrm{~h}$, presumptive isolates were tested for oxidase activity and glucose fermentation.

Clostridium perfringens. Clostridium perfringens counts were determined by International Organization for Standardization standard method (ANON, 1985).

Pseudomonas spp. Pseudomonas counts were determined on cetrimide fucidin cephaloridin agar (AES laboratorie) after $48-72 \mathrm{~h}$ at $22{ }^{\circ} \mathrm{C}$.

Campylobacter jejuni. Egg samples $(20 \mathrm{ml})$ were tested for Campylobacter jejuni by CSAB-Preston (Oxoid). After $18 \mathrm{~h}$ at $42{ }^{\circ} \mathrm{C}$ with microaerophil conditions, samples were plated on Karmali agar and CCDA-Preston (Oxoid). Incubation was performed for 
$48 \mathrm{~h}$ at $42{ }^{\circ} \mathrm{C}$ under microaerophil conditions, and typical colonies were plated on Columbia Blood agar (Merck). After $48 \mathrm{~h}$ at $42{ }^{\circ} \mathrm{C}$, the biochemical identification was performed.

Yersinia enterocolitica. Samples of eggs $(25 \mathrm{ml})$ were tested using the International Organization for Standardization method (ANON, 1994).

\section{Results}

The bacteriological test results of the total count of initial bacteria contaminants in egg white and yolk are expressed as logarithmic numbers, and statistical analysis are shown in Table 1. The average values of the logarithmic number of the bacteria in the pasteurized yolk and egg white were 4.9 and 5.1 respectively; those in the frozenpasteurized yolk and egg white were 5.5 and 4.9; and in the frozen yolk and egg white were 7.0 and 5.9 .

Analysis of variance showed very low probability $(\mathrm{P}<0.01)$ in the hypothesis of the equality of the means on the presence of egg-product contaminant. The alternative hypothesis on its differences could be accepted. That fact made feasible individual analysis between the pairs of the egg-products.

The analysis of the results of the average values of the contaminants' total number pointed to the statistically significant difference between these pairs of pasteurized, frozen-pasteurized and frozen products of the yolk and egg white at the levels of $\mathrm{P}=0.01$ and $\mathrm{P}=0.05$.

Table 1

Statistical analysis of the logarithmic number of total bacterial contaminants in the egg-products

\begin{tabular}{lrcccc}
\hline Samples of the egg-products & $\mathrm{n}$ & $\mathrm{X}_{\mathrm{AVG}}$ & $\mathrm{X}_{\min }-\mathrm{X}_{\max }$ & $\mathrm{SD}$ & $\mathrm{SD}_{\mathrm{x}}$ \\
\hline Egg white & 50 & 6.11 & $4.32-8.56$ & 0.88 & 0.13 \\
Yolk & 50 & 5.87 & $5.00-7.04$ & 0.40 & 0.06 \\
Pasteurized yolk & 50 & 4.89 & $4.00-5.85$ & 0.61 & 0.09 \\
Pasteurized egg-white & 130 & 5.09 & $3.28-8.00$ & 0.91 & 0.08 \\
Frozen-pasteurized egg-white & 30 & 5.48 & $4.58-6.69$ & 0.41 & 0.07 \\
Frozen-pasteurized yolk & 36 & 4.85 & $4.34-5.58$ & 0.32 & 0.05 \\
Frozen yolk & 30 & 6.96 & $6.38-8.72$ & 0.64 & 0.12 \\
Frozen egg-white & 30 & 5.90 & $5.12-7.90$ & 0.67 & 0.12 \\
\hline
\end{tabular}

$\mathrm{n}$ : number of egg samples investigated

$\mathrm{X}_{\mathrm{AVG}}$ : average total count

$\mathrm{X}_{\min }-\mathrm{X}_{\max }$ : range of counts

SD: standard deviation

$\mathrm{SD}_{\mathrm{x}}$ : standard deviation of the sampling distribution of $\overline{\mathrm{x}}$ (standard error of the mean) 
Table 2

Differences between mean values and T-values of the logarithmic number of bacterial contaminants in the egg-products

\begin{tabular}{|c|c|c|c|c|c|c|c|}
\hline & $\mathrm{X}_{\mathrm{AVG}}$ & 1 & 2 & 3 & 4 & 5 & 6 \\
\hline Egg-products & & 4.889 & 5.086 & 5.483 & 4.852 & 6.959 & 5.903 \\
\hline Pasteurized yolk & 4.889 & & & & & & \\
\hline $\mathrm{n}=50$ & $\mathrm{t}$ & - & & & & & \\
\hline Pasteurized egg-white & 5.086 & 0.196 & & & & & \\
\hline$n=150$ & $\mathrm{t}$ & 1.690 & - & & & & \\
\hline Frozen-pasteurized & 5.483 & $0.594 *$ & $0.398^{*}$ & & & & \\
\hline $\mathrm{n}=30$ yolk & $\mathrm{t}$ & 3.685 & 2.812 & - & & & \\
\hline Frozen-pasteurized & 4.852 & 0.037 & 0.234 & $0.631 * *$ & & & \\
\hline $\begin{array}{c}\text { egg-white } \\
n=36\end{array}$ & $\mathrm{t}$ & 0.243 & 1.775 & 3.656 & - & & \\
\hline Frozen yolk & 6.959 & $2.069 *$ & $1.873^{*}$ & $1.475 * *$ & $2.107 *$ & & \\
\hline $\mathrm{n}=70$ & $\mathrm{t}$ & 12.826 & 13.236 & 8.178 & 12.197 & - & \\
\hline Frozen egg-white & 5.903 & $1.014 *$ & $0.817 *$ & $0.419^{*}$ & $1.051 *$ & $1.056^{*}$ & \\
\hline $\mathrm{n}=30$ & $\mathrm{t}$ & 6.282 & 5.774 & 2.324 & 6.083 & 5.854 & - \\
\hline
\end{tabular}

$* \mathrm{P}<0.05$

$* * \mathrm{P}<0.01$

Statistically insignificant differences were seen in the arithmetic average values of the total number of bacteria in the frozen-pasteurized egg-white compared to the pasteurized products, and also in the pasteurized egg-white in relation to the yolk (Table 2). The results of the analysis on the presence of the specific contaminants are shown in Table 3. This showed that the presence of Clostridium spp., Escherichia coli, Proteus spp. and Salmonella spp. in the pasteurized yolk samples were 16\%, 16\%, 14\%, $12 \%$. These bacteria were also detected in the pasteurized egg white, but at lower percentage values: $15.3 \%, 13.8 \%, 10.0 \%$ and $10.8 \%$.

The presence of Staphylococcus aureus in the pasteurized egg white was higher than in yolk ( $4.6 \%$ and $4.0 \%$ respectively); however the Clostridium perfringens results were reversed $(4.0 \%$ and $1.5 \%)$. Other bacteria were not determined.

Egg products, which were preserved by freezing, were the most highly contaminated. The highest number of bacteria from the Clostridium spp. group was isolated in the frozen yolk (26.6\%), frozen egg white $(20 \%)$ and in the frozenpasteurized yolk (13.3\%). Salmonella spp. were isolated less frequently $(16.6 \%, 13.3 \%$ and 10.0\%); the Proteus spp., E. coli, Campylobacter jejuni and Pseudomonas spp. were the most frequent ones in the frozen yolk $(13.3 \%, 20.0 \%, 10.0 \%$ and $10.0 \%)$. 


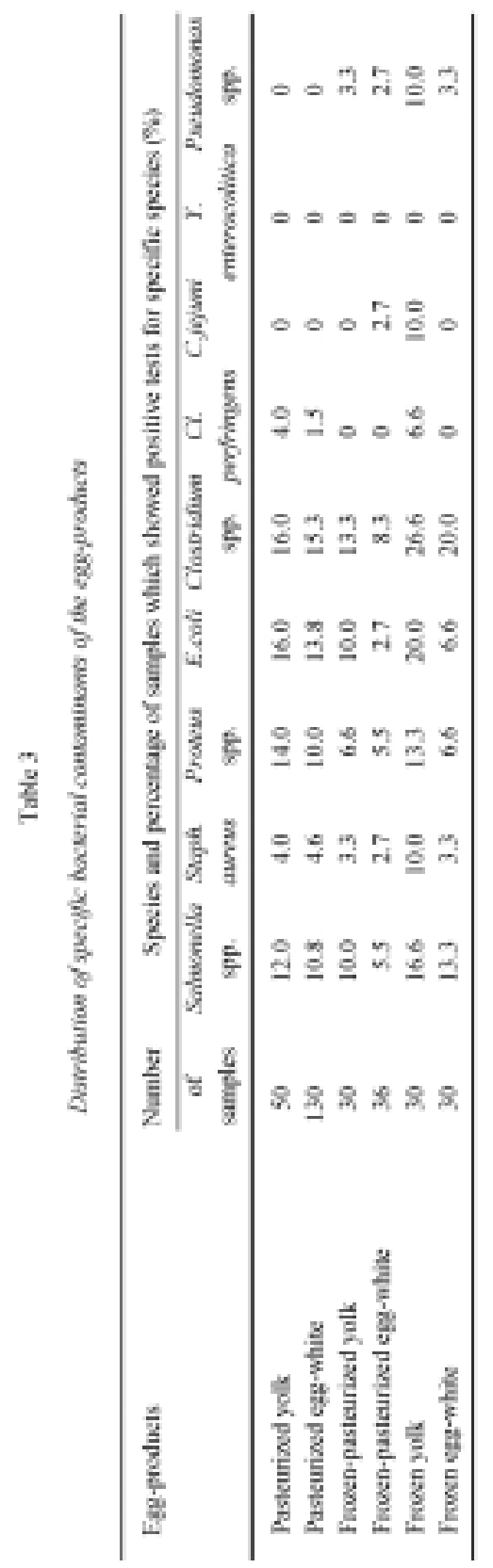

Acta Alimentaria 29, 2000 
We emphasize the fact that within the group of products, which were preserved by means of freezing, the pasteurized egg white showed a far lower presence of all the isolated contaminants.

\section{Conclusion}

According to our research, there is a negligible difference in the degree of contamination by bacteria in untreated yolk and egg white. However, frozen-pasteurized yolk was an exception, because its logarithmic number of bacteria ranged from 4.6 to 6.7 .

On the whole, the process of pasteurization is carried out in order to stop the potential contamination of products by eliminating the pathogenic bacteria (YORK \& DAWSON, 1973). According to our research results, there is a great probability that the customary pasteurization process is not of much help in reducing the initial bacterial microflora of the yolk in relation to the egg-white; the differences in relation to the frozen-pasteurized egg are also negligible. From this point of view, freezing of the yolk after pasteurization is not justified because the total number of bacteria is considerably higher when the yolk and egg white products were only pasteurized.

Processes like pasteurization and freezing, aimed at the improvement of the hygienic quality, are justified only in the case of the technological preparation of the frozen-pasteurized egg white. The products which were preserved by means of temperatures below zero, resulted in the highest degree of bacterial contamination when compared with other groups of tested products. So, we can conclude that the process of freezing did not give the expected results in relation to the inherence of bacterial growth. Freezing as a procedure used for reduction of the initial bacteriological flora, depends on the correct procedures carried out after the primary technological treatment (cleaning, hygienic status of the egg-breaking machine, the areas in which the eggs are broken, packing material and technology, storing conditions and transportation).

Furthermore, we think that aerial microrange plays a very important role in the transmission and inherence of microorganisms to the egg surface, especially after eggbreaking, because of their level of humidity, circulation, dynamic of the particles' movements and stability of the microorganisms in aerosols.

One more important factor is the temperature in the freezing chambers. All the parameters mentioned are less important than a correct technological process of defrosting the egg before usage. The growth of bacterial flora that survives the process of freezing (HUGHEY et al., 1989) is proportional to the temperature and time of thawing. So, due to all the mentioned factors, bacterial flora in frozen products is higher than that found in the other products which were comprised by our research. This was also confirmed by the results of research on the growth of specific bacteria 
contaminants. A high percentage of the presence of the Salmonella spp., Proteus spp., E. coli, Clostridium spp., Pseudomonas and Staphylococus aureus groups correlates with a large logarithmic number of bacteria, especially in those egg-products which were treated at freezing temperatures during the process of technological preparation.

The results of our research indicate that the susceptibility of egg-products to bacteria depends on the primary and secondary technological treatment. In other words, it depends on the initial contamination of the eggs. All in all, the thermal treatment with high temperatures of pasteurization gave better results in reducing bacteriological microflora than the preserving process which is carried out by means of temperatures below zero. Technological preparation of the egg-products carried out by means of low temperatures during the last phase of preparation did not give good results, which would justify this egg-treatment method.

\section{Literature}

ANON (1983): Microbiology of food products general guidance for enumeration of Staphylococcus aureus colony count technique. International Organization for Standardization, Geneve, Switzerland, ISO 6888 .

ANON (1985): Microbiology of food products general guidance for enumeration of Clostridium perfringens colony count technique. International Organization for Standardization, Geneve, Switzerland, ISO 7937.

ANON (1994): Microbiology - general guidance for the detection of presumptive pathogenic Yersinia enterocolitica. International Organization for Standardization, Geneve, Switzerland, ISO 10273.

BAUMGART, J. (1997): Mikrobiologische Untersuchung von Lebensmitteln. B, Behrs Verlag GmbH \& Co., Hamburg, III.3, pp. 1-85.

FrONING, G., IZAT, A., RILEY, G., MAGWIRE, H. (1992): Eggs and egg products. - in: VANDERZANT, C. \& SPLITTOESSER, D. F. (Eds), Compendium of methods for the microbiological examination of foods. American Public Health Ass., Washington D.C., pp. 857-873.

HOOD, S. K. \& ZOTTOLA, E. A. (1987): Electron microscopic study of the adherence properties of Lactobacillus acidophilus. J. Fd. Sci., 52, 791-793.

HugheY, V. L., WILGER, P. A. \& JOHNSON, E. A. (1989): Antibacterial activity of hen egg white lysosyme against Listeria monocytogenes Scott A in foods. Appl. environ. Microbiol., 55, 631-638.

NASCIMENTO, V. P. (1992): Eggshell quality and microbial penetration. Poultry Int., 31, 20-22.

REDFIELD, C. \& DOBSON, C. M. (1988): Sequential super (I) H. NMR - assignments and secondary structure of hen egg white lysosyme in solution. Biochemistry (Wash.), 27, 122-136.

VAN DE GUChTE, M., VAN DER VOSSEN, J. M. B. M., KOK, J. \& VENEMA, G. (1988): Construction of a lactococcal expression of hen egg white lysosyme on Lactococcus lactic subsp. lactis. Appl. environm. Microbiol., 55, 224-228.

YORK, L. R. \& DAWSON, L. E. (1973): Shelf-life of pasteurized liquid whole egg. Poultry Sci., 52, $1657-1658$. 